\title{
The genetic landscape of dural marginal zone lymphomas
}

\author{
Karthik A. Ganapathi ${ }^{1}$, Vaidehi Jobanputra ${ }^{1}$, Fabio Iwamoto${ }^{2}$, Preti Jain ${ }^{1}$, Jinli \\ Chen $^{1}$, Luciano Cascione ${ }^{3}$, Odelia Nahum ${ }^{1}$, Brynn Levy ${ }^{1}$, Yi Xie ${ }^{4}$, Pallavi Khattar ${ }^{5}$, \\ Daniela Hoehn ${ }^{1}$, Francesco Bertoni ${ }^{3}$, Vundavalli V. Murty ${ }^{1}$, Stefania Pittaluga ${ }^{4}$, \\ Elaine S. Jaffe ${ }^{4}$, Bachir Alobeid ${ }^{1}$, Mahesh M. Mansukhani ${ }^{1, *}$ and Govind Bhagat ${ }^{1, *}$ \\ ${ }^{1}$ Department of Pathology and Cell Biology, Columbia University Medical Center, New York, NY, USA \\ ${ }^{2}$ Department of Neurology, Columbia University Medical Center, New York, NY, USA \\ ${ }^{3}$ Institute of Oncology Research and Oncology Institute of Southern Switzerland, Bellinzona, Switzerland \\ ${ }^{4}$ Hematopathology Section, Laboratory of Pathology, National Cancer Institute, Bethesda, MD, USA \\ ${ }^{5}$ Department of Pathology, New York Medical College, Valhalla, NY, USA \\ * These authors have contributed equally to this work \\ Correspondence to: Govind Bhagat, email: gb96@cumc.columbia.edu \\ Mahesh M. Mansukhani, email:mm322@cumc.columbia.edu
}

Keywords: dural marginal zone lymphoma, genome, mutations, TNFAIP3, NOTCH2

Received: April 21, 2016

Accepted: May 14, 2016

Published: May 27, 2016

\section{ABSTRACT}

The dura is a rare site of involvement by marginal zone lymphoma (MZL) and the biology of dural MZL is not well understood. We performed genome-wide DNA copy number and targeted mutational analysis of 14 dural MZL to determine the genetic landscape of this entity. Monoallelic and biallelic inactivation of TNFAIP3 by mutation $(n=5)$ or loss $(n=1)$ was observed in $6 / 9(67 \%)$ dural MZL exhibiting plasmacytic differentiation, including 3 IgG4+ cases. In contrast, activating NOTCH2 mutations were detected in 4/5 (80\%) dural MZL displaying variable monocytoid morphology. Inactivating TBL1XR1 mutations were identified in all NOTCH2 mutated cases. Recurrent mutations in $K L H L 6(n=2)$ and $M L L 2(n=2)$ were also detected. Gains at 6 p25.3 $(n=2)$ and losses at 1p36.32 $(n=3)$ were common chromosomal imbalances, with loss of heterozygosity ( $\mathrm{LOH}$ ) of these loci observed in a subset of cases. Translocations involving the IGH or MALT1 genes were not identified. Our results indicate genetic similarities between dural MZL and other MZL subtypes. However, recurrent and mutually exclusive genetic alterations of TNFAIP3 and NOTCH2 appear to be associated with distinct disease phenotypes in dural MZL.

\section{INTRODUCTION}

Diffuse large B-cell lymphoma is the most common subtype of B-cell non-Hodgkin lymphoma (B-NHL) occurring in the central nervous system (CNS) [1]. In contrast, the meninges are the most common primary (or secondary) site of involvement by low grade B-NHL [2]. The dura is a recognized but uncommon, primary site of occurrence of marginal zone lymphoma (MZL) and rare cases of intra-parenchymal MZLs, occurring in a perivascular location, have also been described [3, 4]. A female predilection has been documented for dural MZLs, and since they often present as solitary masses, they can mimic meningioma's clinically and on imaging studies [5-7]. Most patients are cured following excision and local adjuvant therapy but systemic recurrences have occasionally been reported [8]. Based on their morphologic and phenotypic features, primary dural MZLs are considered similar to mucosa-associated lymphoid tissue (MALT) lymphomas [5, 9]. Intriguingly, a high proportion of dural MZLs (up to 47\%) show a prominent, light chain-restricted plasmacytic component, with a subset displaying clonal IgG4+ plasma cells in the absence of an IgG4-related disorder [6,7].

Data regarding the chromosomal aberrations underlying dural MZLs are limited. Trisomy 3 has been reported as a recurrent cytogenetic abnormality in up to $50 \%$ of cases $[6,7]$. The genomic and mutational 
Table 1: Clinical features of dural MZL patients

\begin{tabular}{|c|c|c|c|c|c|c|c|c|}
\hline Case No. & Age & Sex & Symptoms & Site & Imaging & Therapy & Outcome & $\begin{array}{l}\text { Follow up } \\
\text { duration } \\
\text { (months) }\end{array}$ \\
\hline 1 & 62 & $\mathrm{~F}$ & $\begin{array}{l}\text { Headaches, } \\
\text { right sided } \\
\text { discoordination }\end{array}$ & Cranial Dura & Solitary mass & $\begin{array}{l}\text { RTX, } \\
\text { CTX }\end{array}$ & $\begin{array}{l}\text { Dead- } \\
\text { Unrelated } \\
\text { cause }\end{array}$ & 29 \\
\hline 2 & 48 & $\mathrm{~F}$ & $\begin{array}{l}\text { Left jaw numbness, } \\
\text { left-sided auditory } \\
\text { defects }\end{array}$ & Cranial Dura & Solitary mass & Surgery & $\begin{array}{l}\text { Alive- } \\
\text { NED }\end{array}$ & 77 \\
\hline 3 & 33 & $\mathrm{~F}$ & $\begin{array}{l}\text { Headaches, left } \\
\text { sided weakness, } \\
\text { seizures }\end{array}$ & Cranial Dura & Solitary mass & RTX & $\begin{array}{l}\text { Alive- } \\
\text { NED }\end{array}$ & 26 \\
\hline 4 & 57 & $\mathrm{~F}$ & Headache & $\begin{array}{l}\text { Cranial Dura/ } \\
\text { Parotid }\end{array}$ & Solitary mass & $\begin{array}{l}\text { Surgery, } \\
\text { CTX }\end{array}$ & $\begin{array}{l}\text { Alive- } \\
\text { NED }\end{array}$ & 20 \\
\hline 5 & 45 & $\mathrm{~F}$ & \begin{tabular}{|l}
$\begin{array}{l}\text { Back pain and } \\
\text { spasms }\end{array}$ \\
\end{tabular} & Spinal Dura & Solitary mass & N/A & $\begin{array}{l}\text { Alive- } \\
\text { NED }\end{array}$ & 120 \\
\hline 6 & 42 & $\mathrm{~F}$ & Headaches & Cranial Dura & Solitary mass & RTX & $\begin{array}{l}\text { Alive- } \\
\text { NED }\end{array}$ & 29 \\
\hline 7 & 60 & $\mathrm{~F}$ & $\mathrm{~N} / \mathrm{A}$ & Cranial Dura & Solitary mass & RTX & $\begin{array}{l}\text { Alive- } \\
\text { NED }\end{array}$ & 22 \\
\hline 8 & 34 & $\mathrm{~F}$ & Seizures & Cranial Dura & Solitary mass & CTX & $\begin{array}{l}\text { Alive- } \\
\text { NED }\end{array}$ & 12 \\
\hline 9 & 62 & $\mathrm{~F}$ & $\begin{array}{l}\text { Headaches, right- } \\
\text { sided numbness }\end{array}$ & Cranial Dura & Solitary mass & CTX & $\begin{array}{l}\text { Alive- } \\
\text { NED } \\
\end{array}$ & N/A \\
\hline 10 & 50 & $\mathrm{~F}$ & $\mathrm{~N} / \mathrm{A}$ & Cranial Dura & Solitary mass & N/A & $\mathrm{N} / \mathrm{A}$ & $\mathrm{N} / \mathrm{A}$ \\
\hline 11 & 53 & M & N/A & Cranial Dura & Solitary mass & Surgery & $\begin{array}{l}\text { Alive- } \\
\text { NED }\end{array}$ & 204 \\
\hline 12 & 43 & $\mathrm{~F}$ & $\begin{array}{l}\text { Headache, syncope } \\
\text { andr neurologic } \\
\text { deficits }\end{array}$ & Cranial Dura & Solitary mass & RTX & $\begin{array}{l}\text { Alive- } \\
\text { NED }\end{array}$ & 108 \\
\hline 13 & 42 & $\mathrm{~F}$ & Seizures & Cranial Dura & Solitary mass & N/A & N/A & N/A \\
\hline 14 & 37 & M & $\mathrm{N} / \mathrm{A}$ & Cranial Dura & Solitary mass & N/A & $\mathrm{N} / \mathrm{A}$ & N/A \\
\hline
\end{tabular}

F: female; M: male; N/A: not available; RTX: radiation therapy; CTX: chemotherapy; NED: no evidence of disease

landscape of dural MZLs, however, remains unexplored and the relationship of dural MZL with other MZL subtypes has not been defined [10-12]. In this report, we describe the results of genome-wide DNA copy number and targeted mutational analyses of 14 dural MZL. We detected recurrent and apparently mutually exclusive alterations in two genes critical for normal marginal zone B-cell development and maintenance or homeostasis, NOTCH2 and TNFAIP3, which appear to be associated with distinct disease phenotypes, as well as a variety of additional genomic aberrations in common with other MZL subtypes.

\section{RESULTS AND DISCUSSION}

All fourteen patients were adults (age range 33-62, median 46.5) and there was a marked female predominance (12 females, 2 males). None had a prior history of any hematological malignancy. Imaging studies showed solitary dural-based mass lesions (13 cranial, 1 spinal). All patients underwent surgical resection and 8/14 $(57 \%)$ also received radiation $(n=5)$ and/or chemotherapy $(n=4)$. Ten of $11(90 \%)$ patients with follow up data are alive and disease-free (follow up 12-120 months, median 29 months) and 1 patient died of a disease-unrelated cause (Table 1).

Five cases exhibited variable monocytoid cytomorphology and nine cases showed extensive 
Table 2: Histopathologic, cytogenetic and molecular features of dural MZL

\begin{tabular}{|c|c|c|c|c|c|c|c|c|c|c|c|}
\hline Case No & \begin{tabular}{|l|}
$\begin{array}{l}\text { Plasma } \\
\text { cells }\end{array}$ \\
\end{tabular} & CD20 & CD79a & \begin{tabular}{|l|} 
MUM1/ \\
IRF4
\end{tabular} & CD138 & $\mathbf{K} / \mathbf{L}$ & IgG4 & Ki-67 & Karyotype & FISH & IGH PCR \\
\hline 1 & - & + & + & - & - & Poly & - & $5-10 \%$ & N/A & \begin{tabular}{|l|} 
IGH=NR, \\
3 copies of \\
MALT1 \\
\end{tabular} & Clonal \\
\hline 2 & - & + & + & \pm & - & Poly & - & $5-10 \%$ & N/A & $\begin{array}{l}\text { IGH=NR, } \\
\text { MALT1=NR }\end{array}$ & Clonal \\
\hline 3 & - & + & + & - & - & Poly & - & $5-10 \%$ & Failure & $\begin{array}{l}\mathrm{IGH}=\mathrm{NR}, \\
\text { BCL6=NR, } \\
\text { MALT1=NR }\end{array}$ & Clonal \\
\hline 4 & - & + & + & - & - & Poly & - & $10-20 \%$ & Failure & $\begin{array}{l}\text { IGH=NR, } \\
\text { BCL6=NR, } \\
\text { MALT1=NR } \\
\end{array}$ & Clonal \\
\hline 5 & - & + & N/A & N/A & N/A & Poly & - & N/A & Failure & $\begin{array}{l}\mathrm{IGH}=\mathrm{NR}, \\
\text { MALT1=NR }\end{array}$ & Polyclonal \\
\hline 6 & + & + & + & + & + & K & + & $5-10 \%$ & N/A & $\begin{array}{l}\text { IGH=NR, } \\
\text { BCL6=NR, } \\
\text { MALT1=NR }\end{array}$ & Clonal \\
\hline 7 & + & + & + & + & + & K & + & $10-20 \%$ & N/A & MALT $1=\mathrm{NR}$ & Clonal \\
\hline 8 & + & + & + & + & + & K & - & $40-50 \%$ & Normal & $\begin{array}{l}\text { IGH=NR, } \\
\text { BCL6=NR, } \\
\text { MALT1=NR }\end{array}$ & Clonal \\
\hline 9 & + & + & + & + & N/A & K & - & $5-10 \%$ & N/A & $\begin{array}{l}\mathrm{IGH}=\mathrm{NR}, \\
\text { BCL6=NR, } \\
\text { MALT1=NR } \\
\end{array}$ & Clonal \\
\hline 10 & + & + & + & + & N/A & K & + & $20-50 \%$ & N/A & BCL6=NR & Clonal \\
\hline 11 & + & + & + & + & N/A & K & + & N/A & Normal & $\begin{array}{l}\text { IGH=NR, } \\
\text { BCL6=NR, } \\
\text { MALT1=NR }\end{array}$ & Clonal \\
\hline 12 & + & + & N/A & + & N/A & L & + & N/A & Normal & \begin{tabular}{|l} 
IGH=NR, \\
BCL6=NR, \\
MALT1=NR \\
\end{tabular} & Clonal \\
\hline 13 & + & + & N/A & + & N/A & L & + & N/A & N/A & \begin{tabular}{|l} 
IGH=NR, \\
BCL6=NR, \\
MALT1=NR
\end{tabular} & Failure \\
\hline 14 & + & + & N/A & \pm & $\mathrm{N} / \mathrm{A}$ & K & - & $5-10 \%$ & Normal & BCL6=NR & Clonal \\
\hline
\end{tabular}

N/A: not available; Poly: polytypic; K: kappa light chain restriction; L: lambda light chain restriction; NR: not rearranged

plasmacytic differentiation, with $6 / 9$ cases $(67 \%)$ displaying clonal IgG4+ plasma cells (Figure 1, Table 2). None of the latter had a history of sclerosing pachymeningitis (meningeal IgG4-related disease) or systemic IgG4-related disease before or after the diagnosis of lymphoma, supporting the notion that a subset of MZL represent localized and de novo IgG4-positive lymphoproliferations [7, 13].

G-band chromosome analysis showed normal karyotypes in 4 cases and it failed in 3 cases. Interphase FISH analysis using IGH, MALT1 and BCL6 probes showed no rearrangements but an additional copy of MALT1 was noted as a subclonal change in one MZL (case 1). PCR analysis for immunoglobulin heavy chain $(I G H)$ gene rearrangement showed clonal products in $12 / 13$ (92\%) evaluable cases (Table 2).

Targeted next generation sequencing analysis of 465 cancer-associated genes (Supplementary Table 1), with an average of 684-fold coverage and $>10 \mathrm{X}$ coverage for $99 \%$ of the coding regions (Supplementary Table 2), revealed somatic mutations in all 11 cases $(100 \%)$ with informative results; sequencing failed in 3 MZLs (cases 12-14).

Sequencing and whole genome DNA copy number analysis showed inactivation of TNFAIP3 in 6/9 (67\%) cases exhibiting plasmacytic differentiation (Figure 2, Table 3). Loss of function mutations of TNFAIP3 were identified in 5/9 (56\%) cases, including two novel variants (Supplementary Table 3). Concomitant loss 

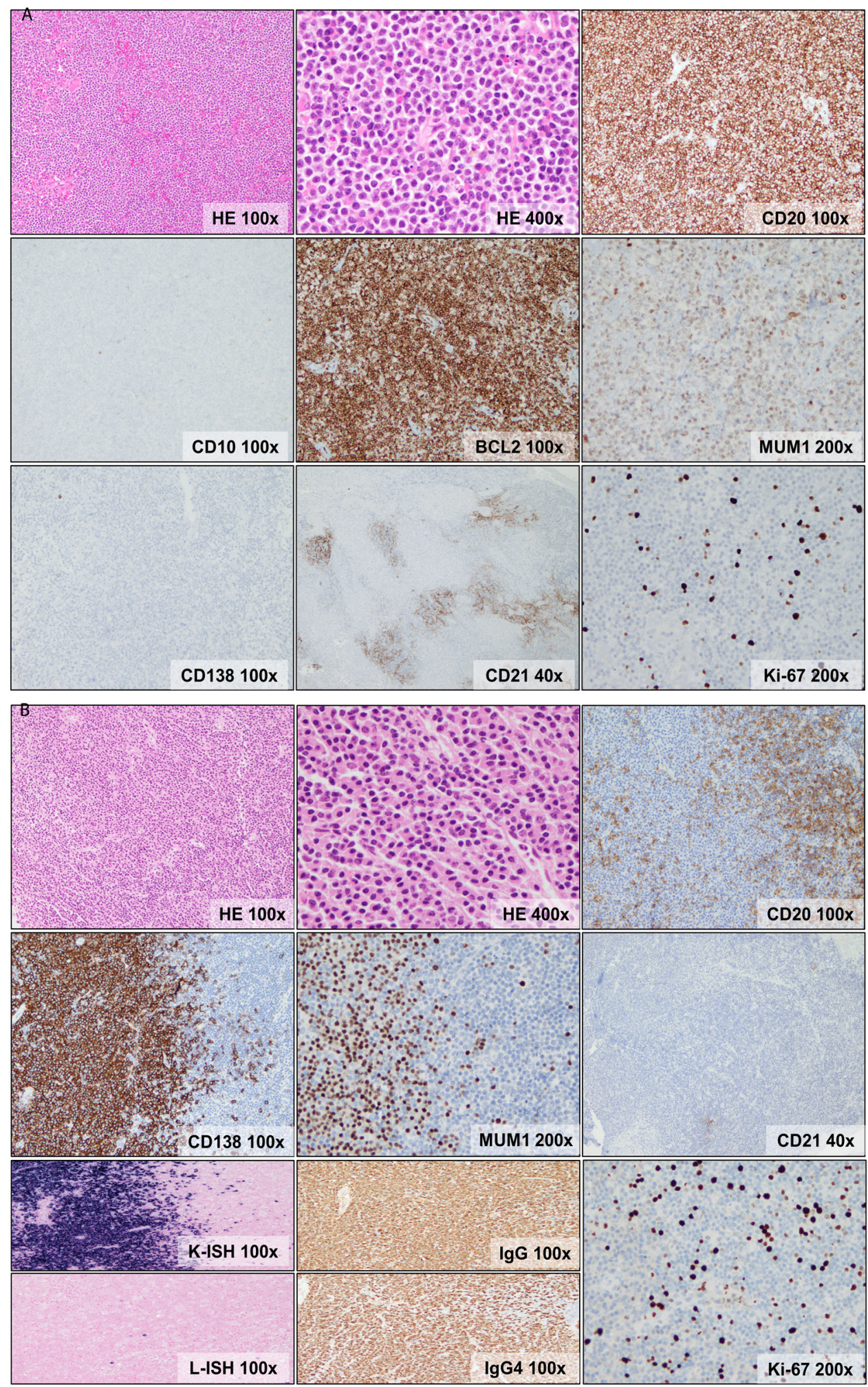

Figure 1: Morphologic and immunophenotypic features of dural MZL. A. Dense, vaguely nodular lymphocytic infiltrate composed of atypical, small lymphocytes exhibiting irregular nuclei, fine chromatin, indistinct nucleoli and abundant pale cytoplasm (monocytoid appearance). The cells are positive for CD20, BCL2, MUM1/IRF4(weak), negative for CD138 and have a low proliferation index (Ki-67<5\%). CD138 shows rare plasma cells. CD21 shows disrupted follicular dendritic cell meshworks. B. Dense vaguely nodular lymphocytic and plasmacytic infiltrate composed of small lymphocytes, some exhibiting plasmacytoid features, and plasma cells. The lymphocytes express CD20, while the plasma cells express CD138 and MUM1/IRF4(bright) and they show kappa light chain restriction and IgG4 expression. CD21 shows rare, small and fragmented follicular dendritic cell meshworks. Ki-67 staining shows a low proliferation index $(<10 \%)$. 
Table 3: Genetic abnormalities in the two morphologic variants of dural MZL

\begin{tabular}{|c|c|c|c|c|c|c|c|c|c|c|c|c|c|c|}
\hline Case No & 1 & 2 & 3 & 4 & 5 & 6 & 7 & 8 & 9 & 10 & 11 & 12 & 13 & 14 \\
\hline PC & $\cdot$ & - & - & - & - & + & + & + & + & + & + & + & + & + \\
\hline $\lg \mathrm{G} 4$ & - & - & - & - & - & + & + & - & - & + & + & + & + & - \\
\hline \multicolumn{15}{|l|}{ NOTCH2 } \\
\hline & & & & & & & & & & & & & & \\
\hline \multicolumn{15}{|l|}{ TNFAIP3 } \\
\hline$T N F A I P 3$ & & & & & & & & & & & & & & \\
\hline \multicolumn{15}{|l|}{$T B L 1 X R 1$} \\
\hline 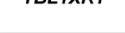 & & & & & & & & & & & & & & \\
\hline \multicolumn{15}{|l|}{$K L H L 6$} \\
\hline KLHLO & & & & & & & & & & & & & & \\
\hline \multirow{2}{*}{\multicolumn{15}{|c|}{ MLL2/KMT2D }} \\
\hline & & & & & & & & & & & & & & \\
\hline \multirow{2}{*}{\multicolumn{15}{|c|}{ CARD11 }} \\
\hline & & & & & & & & & & & & & & \\
\hline \multicolumn{15}{|l|}{ RHOA } \\
\hline & & & & & & & & & & & & & & \\
\hline \multicolumn{15}{|l|}{ MLL/KMT2A } \\
\hline & & & & & & & & & & & & & & \\
\hline \multirow{2}{*}{\multicolumn{15}{|c|}{ TNFRSF14 }} \\
\hline & & & & & & & & & & & & & & \\
\hline \multirow{2}{*}{\multicolumn{15}{|c|}{ PTPRC }} \\
\hline & & & & & & & & & & & & & & \\
\hline
\end{tabular}

Columns represent individual cases and the rows represent genes (two rows for each gene represent the two alleles). PC: plasmacytic differentiation

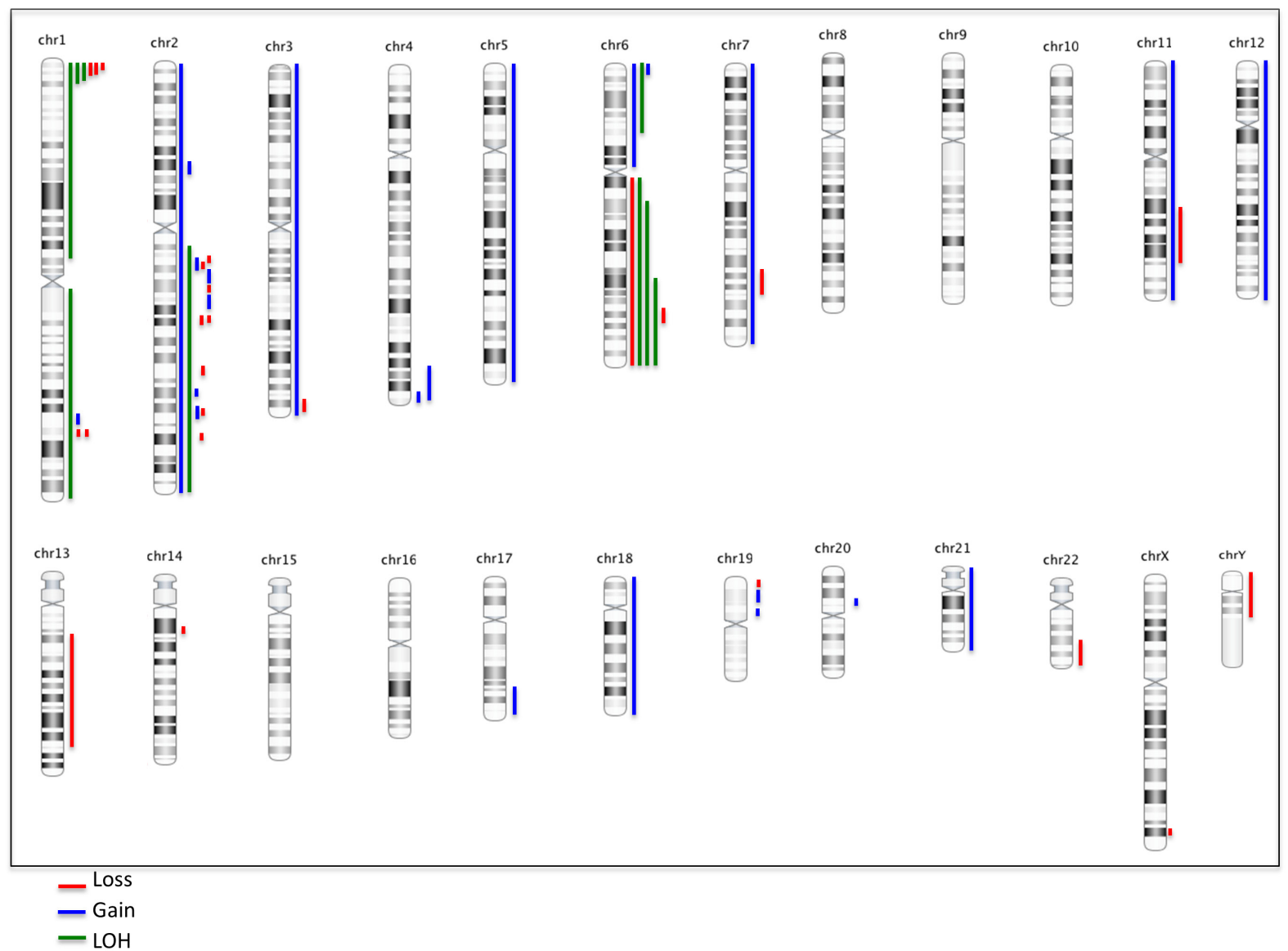

Figure 2: Summary ideogram showing genomic alterations in dural MZL. Blue indicates gains, red indicates losses and green indicates loss of heterozygosity ( $\mathrm{LOH})$. 
of heterozygosity (LOH) at 6q23 was noted in 2 cases, indicating bi-allelic TNFAIP3 inactivation. Additionally, loss of 6q23 involving the TNFAIP3 locus and LOH in this region were seen in one case each $(1 / 9,11 \%)$; poor DNA quality precluded assessment of mutations in these cases (Supplementary Table 4).

TNFAIP3 (also known as A20) is a negative regulator of NF- $\mathrm{kB}$ signaling $[14,15]$. B-cell specific deletion of TNFAIP3 in mice results in mislocalization of marginal zone B-cells and defective antigen-induced B-cell maturation [16]. TNFAIP3-deficient B-cells are hyper-reactive to antigen stimulation, leading to enhanced proliferation and survival. Mice with B-cells lacking TNFAIP3 also demonstrate plasma cell hyperplasia and chronic inflammation, and they develop autoimmune disorders upon aging [16]. Recurrent inactivating mutations and/or genomic loss of TNFAIP3 have been described in Hodgkin and non-Hodgkin lymphomas, including diffuse large B-cell lymphoma (DLBCL) $[17,18]$, extranodal MZL and nodal MZL $[10,11,19]$. However, an association with plasmacytic differentiation has not been reported for any type of B-NHL harboring this genetic alteration.

Activating NOTCH2 mutations were identified in $4 / 5(80 \%)$ cases manifesting variable monocytoid features, including three novel variants (Table 3, Supplementary Table 3). Bi-allelic NOTCH2 aberrations were identified in two cases; bi-allelic mutations in one and a mutation accompanied by $\mathrm{LOH}$ at $1 \mathrm{p} 11$, containing the NOTCH2 locus, in another. NOTCH2 mutations were either located in the transactivation domain (TAD) or the proline/ glutamate/serine/threonine-rich (PEST) domain, resulting in deletion of protein degradation motifs that regulate protein stability [20].

$\mathrm{NOTCH} 2$ is indispensable for marginal zone B-cell development and maintenance [21]. Targeted deletion of NOTCH2 in murine B-cells results in the complete absence of marginal zone B-cells and their precursors i.e. transitional T2 B-cells [22]. Conversely, constitutively active $\mathrm{NOTCH} 2$ signaling in murine B-cells leads to an expansion of marginal zone B-cells at the expense of follicular B-cells. However, mice with constitutive NOTCH2 expression do not develop B-cell lymphoma, suggesting that sustained NOTCH2 signaling alone is insufficient for B-cell lymphomagenesis [23]. The majority of documented NOTCH2 mutations in B-NHLs target the C-terminal transactivation (TAD) domain or the proline/glutamate/serine/threonine-rich (PEST) domain, resulting in increased protein stability and uncontrolled activation of the NOTCH2 and NF-kB pathways [24]. NOTCH2 activating mutations have been identified in a variety of lymphomas, including splenic MZL, follicular lymphoma (FL) and DLBCL, and their presence is thought to predict an aggressive clinical course in certain B-NHLs [24-28]. Until now, NOTCH2 mutations have not been described in non-splenic MZL.

Of note, recurrent TBL1XR1 mutations $(4 / 11,36 \%)$ were only seen in association with $\mathrm{NOTCH} 2$ mutations (Table 3, Supplementary Table 3), which could indicate a co-operative role for these mutations in lymphomagenesis. TBL1XR1 is a transcriptional regulator of the Wnt/ $\beta$ catenin and NF- $\kappa B$ pathways and recurrent mutations of
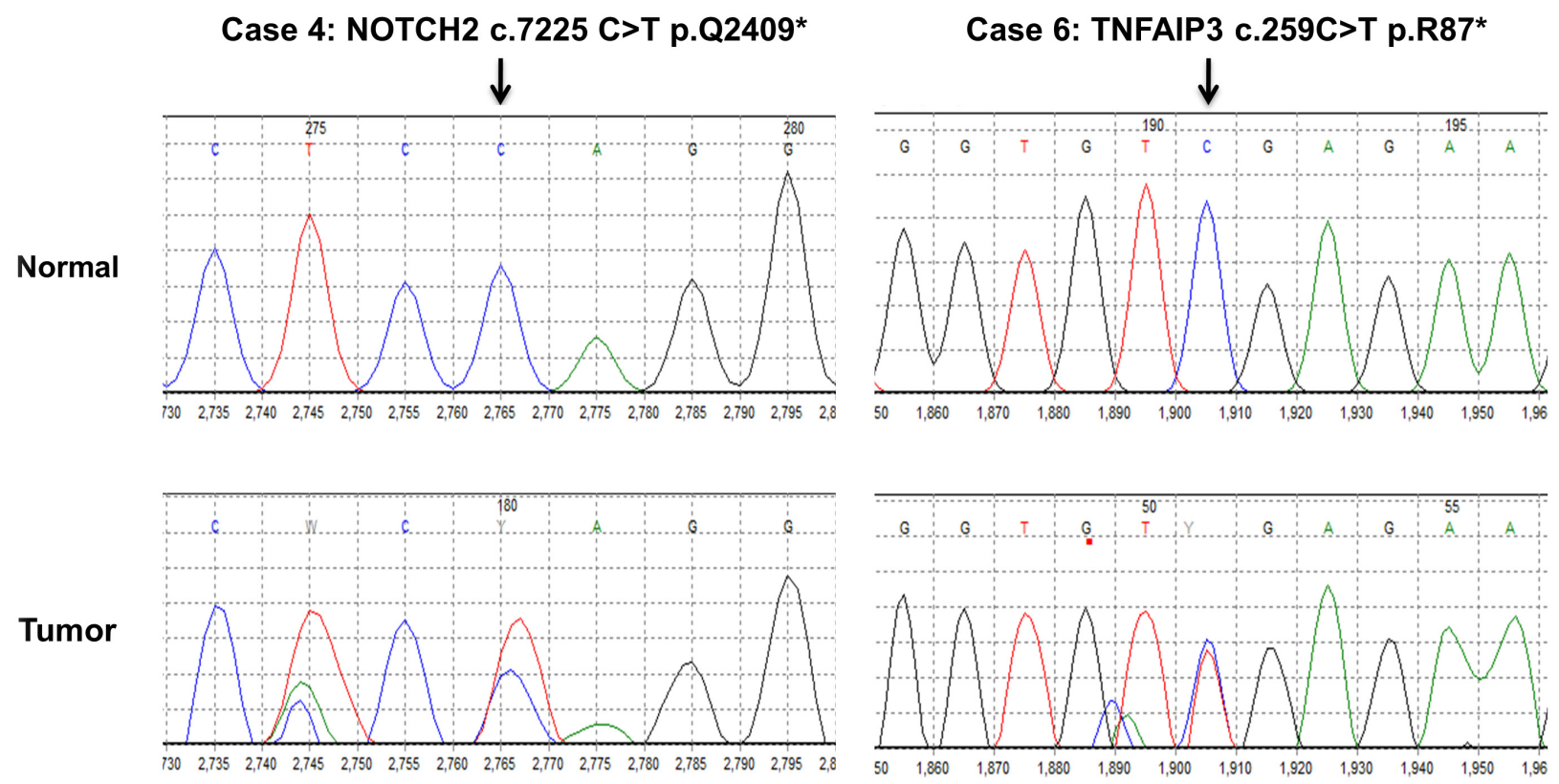

Figure 3: Sanger confirmation of $\mathrm{NOTCH} 2$ and TNFAIP3 mutations. 
this gene have previously been described in other subtypes of B-NHL, especially splenic MZL and primary CNS DLBCL $[28,29]$. Other recurrently mutated genes in dural MZL included KLHL6 $(2 / 11,18 \%)$ and MLL2/KMT2D $(2 / 11,18 \%)$ (Table 3$)$. A role in B-cell receptor signaling has been proposed for KLHL6 and recurrent KLHL6 mutations have been described in chronic lymphocytic leukemia [30]. MLL2/KMT2D plays an important role in chromatin remodeling and transcriptional regulation and loss of function MLL2/KMT2D mutations have been described in a variety of B-NHL, including splenic MZL [28, 31, 32]. Non-recurrent mutations of CARD11, RHOA, MLL/KMT2A, TNFRSF14, and PTPRC were also identified and the variant allele frequencies of some mutations suggested that they might represent secondary events (Supplementary Table 3 ).

The recurrent mutations described above were confirmed by Sanger sequencing (Supplementary Table 3, representative examples are shown in Figure 3).

Whole genome DNA copy number analysis showed chromosomal alterations in 12 of 13 cases (median - 4 per case, range 1-9), including recurrent aberrations involving 1p36.32 [loss, 3/13 (23\%), LOH, 3/13 (23\%)], with the minimal common region of aberration encompassing TNFRSF14, PRDM16, RPL22 and CAMTA1 genes, and 6p25.3 [gain, 2/13 (15\%), LOH, 1/13 (8\%)], encompassing the IRF4 gene. Whole chromosome abnormalities were identified in $2 / 13(15 \%)$ cases, including one case that showed gains of 3 and 18 (Figure 2, Supplementary Table 4), which were not observed by FISH analysis, potentially representing subclonal changes. The observed genomic changes are similar to those described previously in other MZL subtypes, although the frequencies appear to differ $[10,11]$. Importantly, our findings suggest that in contrast to other MZL subtypes, aberrations of chromosomes 3 and 18 are infrequent in primary dural MZL $[6,7]$.

In summary, we report recurrent and apparently mutually exclusive genetic alterations of TNFAIP3 and $\mathrm{NOTCH}_{2}$ in dural MZL, in addition to novel and previously described mutations and genomic aberrations associated with other MZL subtypes. Contrary to observations in other B-NHL, these genetic aberrations do not appear to portend an aggressive course in dural MZL. Until now, specific genotype-phenotype correlations have not been reported for other MZL subtypes and our findings raise the possibility of at least two independent pathways leading to dysregulated $\mathrm{NF}-\kappa \mathrm{B}$ signaling in dural MZL that our associated with distinct disease phenotypes. However, larger studies with longer follow up are warranted to clarify the prognostic implications and functional consequences of the different genetic lesions discerned.

\section{MATERIALS AND METHODS}

\section{Case selection}

Fourteen primary dural MZL cases with adequate formalin-fixed paraffin-embedded (FFPE) tissue $(>50 \%$ tumor) were identified in the archives of the Departments of Pathology, Columbia University Medical Center, New York $(\mathrm{n}=9)$ and the National Cancer Institute, Bethesda, Maryland $(n=5)$. The latter were part of a previously published series [7]. Clinical, radiological and treatment data were reviewed for all cases. The study was performed using protocols approved by the institutional review boards of both institutions and in accordance with the principles of the Declaration of Helsinki.

\section{Morphologic and immunophenotypic evaluation}

Hematoxylin and Eosin (H\&E) stained FFPE tissue sections were reviewed to assess cyto-architectural features. Immunohistochemistry and in-situ hybridization was performed with the following panel of antibodies and probes; CD20 (clone MJ1); CD10 (clone 56C6); CD5 (clone 4C7); BCL6 (clone LN22); BCL2 (clone D5); CD21 (clone PA0171); kappa (clone ISH-5748A), lambda (clone ISH-5770A), all from Leica, IL, USA; CD79a (clone AP18); Cyclin D1 (clone SP4-R); CD138 (clone B-A38); CD21 (clone PA0171); IgG (clone 1210208A); IgG4 (clone 1123107A); Ki-67 (clone 30-9), all from Ventana, AZ, USA; and MUM-1 (clone MUM1p) from DAKO, CA, USA. Staining was performed with automated stainers (Ventana Benchmark Ultra and Leica Bond III) and visualized with the UltraView Universal and Bond polymer DAB detection kits according to the manufacturer's protocols.

\section{Cytogenetic analysis}

Giemsa (G) banding and karyotype analysis was performed on metaphase preparations from fresh tumor specimens $(\mathrm{n}=7)$ after short-term (24 hr.) culture using standard techniques and karyotypes were described according to the International System for Human Cytogenetic Nomenclature [33].

Fluorescence in situ hybridization (FISH) analysis using IGH $(\mathrm{n}=11), \operatorname{MALT1}(\mathrm{n}=12)$ and BCL6 $(\mathrm{n}=10)$ break-apart probes (Abbott Laboratories, Abbott Park, Illinois, USA) was performed on FFPE tissue sections. FISH signals were scored on 200-500 interphase nuclei after counterstaining with DAPI using a Nikon Eclipse 600 microscope and captured with the Cytovision Imaging system (Applied Imaging, Santa Clara, CA). 


\section{Immunoglobulin heavy chain (IGH) gene rearrangement analysis}

DNA was extracted from FFPE tissue and fluorescent polymerase chain reaction (PCR) was performed using the BIOMED-2 primers, followed by capillary gel electrophoresis, to ascertain the presence of clonal $I G H$ gene rearrangements, as described [34].

\section{Next generation sequencing}

Targeted next generation sequencing was successful in 11 of 14 cases using a panel comprising 465 cancerassociated genes (Supplementary Table 1). Fifty to $250 \mathrm{ng}$ of DNA, extracted using the Qiamp mini kit or the Qiamp FFPE kit (Qiagen, Germantown, USA) was fragmented to a median of 150-200bp, by sonication. Following endrepair and 3' adenylation of the fragments, and ligation of double-stranded sequencing and indexing adaptors to ends, target capture and enrichment was performed with the Sure Select Hybrid Capture system (Agilent Technologies, Santa Clara, USA), using custom designed probes. Libraries were then quantified using qPCR, diluted to $2 \mathrm{nM}$ and pooled, prior to cluster generation and analysis on Illumina HiSeq2500, using Illumina TruSeq v3 chemistry (San Diego, USA) and 100bp paired-end reads (up to 9 indexed samples per run). Fastq files of reads where over $70 \%$ of reads were above Q30, were demultiplexed with CASAVA, and samples with at least $6 \mathrm{~Gb}$ of data were used for mapping and variant calling using NextGene Software (Softgenetics, State College, USA), using the following criteria: 0 allowable ambiguous alignments, at least $90 \%$ of a read having to match the reference genome, software set to detect large indels, hiding the unmatched ends of reads, with at least $10 \%$ variant allelic fraction, and at least 3 variant reads to call a variant.

After annotation, the variants were cross referenced with those in the 1000 Genomes Project, OMIM, dbSNP, and the Exome Variant Server. Variants with an allele prevalence $>1 \%$ in the 1000 genomes project were excluded. Common variants present in our departmental database of variants identified in prior constitutional exome analysis, non-pathogenic variants reported in dbSNP, and low quality calls were filtered out. The remaining variants were submitted for manual curation and variant prioritization with visual review of alignments. Synonymous variants and intronic variants greater than 2 bp from the coding sequence were excluded. Variants were manually cross-referenced with the Catalog of Somatic Variants in Cancer (COSMIC) and those that were not known "hot spot" mutations or had not been previously reported as potential driver variants were analyzed by PROVEAN and SIFT algorithms (Supplementary Table 2). Matched normal tissue samples (bone marrow aspirate) were available for two MZLs (cases 4 and 9). Variants present in the normal sample were excluded from analysis in these cases.

\section{Whole genome copy number and loss of heterozygosity $(\mathrm{LOH})$ analysis}

Genome-wide DNA copy number and LOH analysis was performed in 13 of 14 cases using the Affymetrix OncoScan FFPE assay (Affymetrix, CA, USA), which utilizes molecular inversion probe technology and is optimized to work on DNA derived from FFPE tissue samples [35].

Sample preparation, hybridization and scanning were performed according to the manufacturer's specifications. Analysis was performed using the Affymetrix Chromosome Analysis Suite 2.0 (ChAS) and Nexus Copy Number 7.5 software (Biodiscovery, Inc. CA, USA). All copy number alterations and regions of $\mathrm{LOH}$ recognized by the software were verified visually to determine erroneous calls and identify clonal or subclonal gains and losses not detected by the software. Analysis was restricted to gains and losses $>1 \mathrm{Mb}$ in length (Supplementary Table 4). Genomic alterations were reported based on the NCBI build 37 (hg19) of the human genome and cancer-associated genes were curated from the Cancer Gene Census (COSMIC v61 Release; http:// www.sanger.ac.uk/genetics/CGP/Census/)

\section{Sanger Sequencing}

Recurrent mutations deemed to be pathogenic were confirmed by Sanger sequencing according to standard methods. Briefly, PCR products obtained with specific primers flanking the mutation of interest were treated with exonuclease and shrimp alkaline phosphatase to remove remaining primers and dNTPs, and used as substrates for cycle sequencing using the BidDye Terminator Version 3.1 chemistry (Thermo Fisher, Springfield Township, USA), analyzed on an ABI 3130XL capillary sequencer (ThermoFisher, USA), and evaluated using Mutation Surveyor (Softgenetics, State College, USA).

\section{CONFLICTS OF INTEREST}

The authors report no disclosures, financial interests or conflicts of interest.

\section{Editorial note}

This paper has been accepted based in part on peerreview conducted by another journal and the authors' response and revisions as well as expedited peer-review in Oncotarget. 


\section{REFERENCES}

1. Swerdlow SH, Campo E, Harris NL, Jaffe ES, Pileri SA, Stein H, Thiele J, Vardiman JW. (2008). WHO classification of tumours of haematopoietic and lymphoid tissues. (Lyon: International Agency for Research on Cancer).

2. Spectre G, Gural A, Amir G, Lossos A, Siegal T and Paltiel O. Central nervous system involvement in indolent lymphomas. Annals of oncology. 2005; 16(3):450-454.

3. Papanicolau-Sengos A, Wang-Rodriguez J, Wang HY, Lee RR, Wong A, Hansen LA, Mahooti S and Rashidi HH. Rare case of a primary non-dural central nervous system low grade B-cell lymphoma and literature review. International journal of clinical and experimental pathology. 2012; 5(1):89-95.

4. Ueba T, Okawa M, Abe H, Inoue T, Takano K, Hayashi $\mathrm{H}$, Nabeshima K and Oshima K. Central nervous system marginal zone B-cell lymphoma of mucosa-associated lymphoid tissue type involving the brain and spinal cord parenchyma. Neuropathology. 2013; 33(3):306-311.

5. Kumar S, Kumar D, Kaldjian EP, Bauserman S, Raffeld M and Jaffe ES. Primary low-grade B-cell lymphoma of the dura: a mucosa associated lymphoid tissue-type lymphoma. Am J Surg Pathol. 1997; 21(1):81-87.

6. Tu PH, Giannini C, Judkins AR, Schwalb JM, Burack R, O’Neill BP, Yachnis AT, Burger PC, Scheithauer BW and Perry A. Clinicopathologic and genetic profile of intracranial marginal zone lymphoma: a primary low-grade CNS lymphoma that mimics meningioma. J Clin Oncol. 2005; 23(24):5718-5727.

7. Venkataraman G, Rizzo KA, Chavez JJ, Streubel B, Raffeld M, Jaffe ES and Pittaluga S. Marginal zone lymphomas involving meningeal dura: possible link to IgG4-related diseases. Mod Pathol. 2011; 24(3):355-366.

8. Iwamoto FM, DeAngelis LM and Abrey LE. Primary dural lymphomas: a clinicopathologic study of treatment and outcome in eight patients. Neurology. 2006; 66(11):17631765 .

9. Kambham N, Chang Y and Matsushima AY. Primary lowgrade B-cell lymphoma of mucosa-associated lymphoid tissue (MALT) arising in dura. Clin Neuropathol. 1998; 17(6):311-317.

10. Kwee I, Rancoita PM, Rinaldi A, Ferreri AJ, Bhagat G, Gascoyne RD, Canzonieri V, Gaidano G, Doglioni C, Zucca E, Ponzoni M and Bertoni F. Genomic profiles of MALT lymphomas: variability across anatomical sites. Haematologica. 2011; 96(7):1064-1066.

11. Rinaldi A, Mian M, Chigrinova E, Arcaini L, Bhagat G, Novak U, Rancoita PM, De Campos CP, Forconi F, Gascoyne RD, Facchetti F, Ponzoni M, Govi S, et al. Genome-wide DNA profiling of marginal zone lymphomas identifies subtype-specific lesions with an impact on the clinical outcome. Blood. 2011; 117(5):1595-1604.

12. Streubel B, Huber D, Wohrer S, Chott A and Raderer
M. Frequency of chromosomal aberrations involving MALT1 in mucosa- associated lymphoid tissue lymphoma in patients with Sjogren's syndrome. Clinical Cancer Research. 2004; 10(2):476-480.

13. Brenner I, Roth S, Puppe B, Wobser M, Rosenwald A and Geissinger E. Primary cutaneous marginal zone lymphomas with plasmacytic differentiation show frequent $\mathrm{IgG} 4$ expression. Mod Pathol. 2013; 26(12):1568-1576.

14. Catrysse L, Vereecke L, Beyaert R and van Loo G. A20 in inflammation and autoimmunity. Trends in immunology. 2014; 35(1):22-31.

15. Wertz IE, O'Rourke KM, Zhou H, Eby M, Aravind L, Seshagiri S, Wu P, Wiesmann C, Baker R, Boone DL, Ma A, Koonin EV and Dixit VM. De-ubiquitination and ubiquitin ligase domains of A20 downregulate NF-kappaB signalling. Nature. 2004; 430(7000):694-699.

16. Chu Y, Vahl JC, Kumar D, Heger K, Bertossi A, Wojtowicz E, Soberon V, Schenten D, Mack B, Reutelshofer M, Beyaert R, Amann K, van Loo G, et al. B cells lacking the tumor suppressor TNFAIP3/A20 display impaired differentiation and hyperactivation and cause inflammation and autoimmunity in aged mice. Blood. 2011; 117(7):22272236.

17. Kato M, Sanada M, Kato I, Sato Y, Takita J, Takeuchi K, Niwa A, Chen Y, Nakazaki K, Nomoto J, Asakura Y, Muto $\mathrm{S}$, Tamura A, et al. Frequent inactivation of A20 in B-cell lymphomas. Nature. 2009; 459(7247):712-716.

18. Compagno M, Lim WK, Grunn A, Nandula SV, Brahmachary M, Shen Q, Bertoni F, Ponzoni M, Scandurra M, Califano A, Bhagat G, Chadburn A, Dalla-Favera R, et al. Mutations of multiple genes cause deregulation of NFkappaB in diffuse large B-cell lymphoma. Nature. 2009; 459(7247):717-721.

19. Novak U, Rinaldi A, Kwee I, Nandula SV, Rancoita PM, Compagno M, Cerri M, Rossi D, Murty VV, Zucca E, Gaidano G, Dalla-Favera R, Pasqualucci L, et al. The NF\{kappa\}B negative regulator TNFAIP3 (A20) is inactivated by somatic mutations and genomic deletions in marginal zone lymphomas. Blood. 2009; 113(20):4918-4921.

20. Kopan R and Ilagan MX. The canonical Notch signaling pathway: unfolding the activation mechanism. Cell. 2009; 137(2):216-233.

21. Pillai S and Cariappa A. The follicular versus marginal zone B lymphocyte cell fate decision. Nat Rev Immunol. 2009; 9(11):767-777.

22. Saito T, Chiba S, Ichikawa M, Kunisato A, Asai T, Shimizu K, Yamaguchi T, Yamamoto G, Seo S, Kumano K, Nakagami-Yamaguchi E, Hamada Y, Aizawa S, et al. Notch2 is preferentially expressed in mature B cells and indispensable for marginal zone B lineage development. Immunity. 2003; 18(5):675-685.

23. Hampel F, Ehrenberg S, Hojer C, Draeseke A, MarschallSchroter G, Kuhn R, Mack B, Gires O, Vahl CJ, SchmidtSupprian M, Strobl LJ and Zimber-Strobl U. CD19- 
independent instruction of murine marginal zone B-cell development by constitutive Notch2 signaling. Blood. 2011; 118(24):6321-6331.

24. Zhang X, Shi Y, Weng Y, Lai Q, Luo T, Zhao J, Ren G, Li W, Pan H, Ke Y, Zhang W, He Q, Wang Q, et al. The truncate mutation of Notch2 enhances cell proliferation through activating the NF-kappaB signal pathway in the diffuse large B-cell lymphomas. PloS one. 2014; 9(10):e108747.

25. Arcaini L, Rossi D, Lucioni M, Nicola M, Bruscaggin A, Fiaccadori V, Riboni R, Ramponi A, Ferretti VV, Cresta $\mathrm{S}$, Casaluci GM, Bonfichi M, Gotti M, et al. The NOTCH pathway is recurrently mutated in diffuse large B-cell lymphoma associated with hepatitis $\mathrm{C}$ virus infection. Haematologica. 2015; 100(2):246-252.

26. Karube K, Martinez D, Royo C, Navarro A, Pinyol M, Cazorla M, Castillo P, Valera A, Carrio A, Costa D, Colomer D, Rosenwald A, Ott G, et al. Recurrent mutations of NOTCH genes in follicular lymphoma identify a distinctive subset of tumours. The Journal of pathology. 2014; 234(3):423-430.

27. Kiel MJ, Velusamy T, Betz BL, Zhao L, Weigelin HG, Chiang MY, Huebner-Chan DR, Bailey NG, Yang DT, Bhagat G, Miranda RN, Bahler DW, Medeiros LJ, et al. Whole-genome sequencing identifies recurrent somatic NOTCH2 mutations in splenic marginal zone lymphoma. The Journal of experimental medicine. 2012; 209(9):15531565.

28. Rossi D, Trifonov V, Fangazio M, Bruscaggin A, Rasi S, Spina V, Monti S, Vaisitti T, Arruga F, Fama R, Ciardullo C, Greco M, Cresta S, et al. The coding genome of splenic marginal zone lymphoma: activation of $\mathrm{NOTCH} 2$ and other pathways regulating marginal zone development. The Journal of experimental medicine. 2012; 209(9):1537-1551.

29. Gonzalez-Aguilar A, Idbaih A, Boisselier B, Habbita N, Rossetto M, Laurenge A, Bruno A, Jouvet A, Polivka M, Adam C, Figarella-Branger D, Miquel C, Vital A, et al. Recurrent mutations of MYD88 and TBL1XR1 in primary central nervous system lymphomas. Clinical cancer research. 2012; 18(19):5203-5211.
30. Puente XS, Pinyol M, Quesada V, Conde L, Ordonez GR, Villamor N, Escaramis G, Jares P, Bea S, Gonzalez-Diaz M, Bassaganyas L, Baumann T, Juan M, et al. Wholegenome sequencing identifies recurrent mutations in chronic lymphocytic leukaemia. Nature. 2011; 475(7354):101-105.

31. Pasqualucci L, Dominguez-Sola D, Chiarenza A, Fabbri G, Grunn A, Trifonov V, Kasper LH, Lerach S, Tang H, Ma J, Rossi D, Chadburn A, Murty VV, et al. Inactivating mutations of acetyltransferase genes in B-cell lymphoma. Nature. 2011; 471(7337):189-195.

32. Pasqualucci L, Trifonov V, Fabbri G, Ma J, Rossi D, Chiarenza A, Wells VA, Grunn A, Messina M, Elliot O, Chan J, Bhagat G, Chadburn A, et al. Analysis of the coding genome of diffuse large B-cell lymphoma. Nature genetics. 2011; 43(9):830-837.

33. International Standing Committee on Human Cytogenetic Nomenclature., Shaffer LG, McGowan-Jordan J and Schmid M. (2013). ISCN 2013 : an international system for human cytogenetic nomenclature (2013). (Basel: Karger).

34. van Dongen JJ, Langerak AW, Bruggemann M, Evans PA, Hummel M, Lavender FL, Delabesse E, Davi F, Schuuring E, Garcia-Sanz R, van Krieken JH, Droese J, Gonzalez D, et al. Design and standardization of PCR primers and protocols for detection of clonal immunoglobulin and T-cell receptor gene recombinations in suspect lymphoproliferations: report of the BIOMED-2 Concerted Action BMH4-CT98-3936. Leukemia. 2003; 17(12):2257-2317.

35. Wang $Y$, Cottman $M$ and Schiffman JD. Molecular inversion probes: a novel microarray technology and its application in cancer research. Cancer genetics. 2012; 205(7-8):341-355. 